\title{
Synthesis and Photophysical Properties of a Poly(Methyl Methacrylate) Polymer with Carbazolyl Side Groups
}

\author{
Tatiana D. Martins, ${ }^{a}$ Richard G. Weiss ${ }^{*, b}$ and Teresa D. Z. Atvars ${ }^{*, a}$ \\ ${ }^{a}$ Instituto de Química, Universidade Estadual de Campinas, 13084-971 Campinas-SP, Brazil \\ ${ }^{b}$ Department of Chemistry, Georgetown University, Washington, DC 20057-1227, USA
}

As propriedades fotofísicas de um poli(metacrilato de metila) (PMMA) contendo 1,6 mol \% de grupos etil-carbazolila aleatoriamente distribuídos pela cadeia, foram estudadas pelas técnicas de espectroscopia de fluorescência em condições fotoestacionárias e com resolução temporal. O material foi preparado a partir da esterificação do poli(metacrilato de metila- $c o$-ácido metacrílico) com 9H-carbazolila-9-etanol. A temperatura ambiente, o espectro de fluorescência que se obtém para a amostra em solução é devido ao lumóforo isolado. Em filme, suas características espectroscópicas se tornam mais complexas, com contribuições do lumóforo isolado, dímeros formados no estado eletrônico fundamental e excímeros. A $77 \mathrm{~K}$, a emissão obtida das amostras, tanto em filme quanto em solução, apresenta também a contribuição da fosforescência, que ocorre na mesma região espectral que a emissão de fluorescência dos agregados emissores. Os diversos tipos de relaxações mecânicas do polímero puderam ser observados através dos espectros de fluorescência do filme, obtidos na faixa de temperatura de 30 a $410 \mathrm{~K}$ e são similares àqueles relativos ao PMMA. Os dados obtidos por calorimetria diferencial de varredura (DSC) e análise térmica dinâmico-mecânica (DMTA) são comparados aos dados fornecidos pela espectroscopia de fluorescência e as temperaturas onde ocorrem estas relaxações puderam ser determinadas. Assim os processos da $\gamma$-relaxação, que é resultante de movimentos de pequenos segmentos de cadeia, ocorrem a 120-130 K (observados por espectroscopia de fluorescência), a $\beta$-relaxação, resultante dos movimentos de grupos éster laterais (observada por DMTA e espectroscopia de fluorescência), a $310 \mathrm{~K}$ e $\alpha$-relaxação (temperatura de transição vítrea) ocorre a $380 \mathrm{~K}$ (observada por DSC e DMTA).

The photophysical properties of solutions and films of poly(methyl methacrylate) (PMMA) containing $1.6 \mathrm{~mol} \%$ of randomly distributed pendant ethyl carbazolyl groups have been studied under steady-state and time-resolved conditions. The polymer was prepared by esterification of poly(methyl methacrylate-co-methacrylic acid) by $9 \mathrm{H}$-carbazole-9-ethanol. At room temperature, the steady-state fluorescence spectrum is attributed to isolated lumophores in solution, but is much more complex in films where emission is detected from isolated groups, ground-state dimers and excimers. At $77 \mathrm{~K}$, emission from both solutions and films contains a component of phosphorescence whose wavelengths overlap fluorescence from excited ground-state dimers and excimers. From the temperature dependence of the steady-state emission spectra of the films, recorded from 30 to $410 \mathrm{~K}$, several types of relaxation processes are identified at temperatures similar to those of unmodified PMMA. Data by differential scanning calorimetry (DSC), dynamic mechanical thermal analysis (DMTA) and fluorescence spectroscopy are compared. They include the $\gamma$-relaxations from motions of small segments of the chains at 120-130 K (by fluorescence spectroscopy), the $\beta$-relaxation from motions of lateral ester groups (by DMTA and fluorescence spectroscopy) at $310 \mathrm{~K}$ and $\alpha$-relaxations (glass transition onset) at $380 \mathrm{~K}$ (by DSC and DMTA).

Keywords: carbazole, carbaxolyl-based poly(methyl methacrylate), luminescence, temperature dependence, relaxation processes

*e-mail: tatvars@iqm.unicamp.br; weissr@georgetown.edu 


\section{Introduction}

Chemical modification of low-cost materials is an attractive methodology for obtaining new, high value materials with specific properties. ${ }^{1-3}$ One approach to this end involves copolymerizations in which a small mole fraction of a second monomer is used to introduce a new property that is absent in the homopolymer.

For example, poly(methyl methacrylate) (PMMA) is an inexpensive, non-luminescent material with several technological applications in microengineering, microelectronics and biotechnology ${ }^{4-6}$ either alone or as part of a polymer blend. ${ }^{7,8}$ As a component of a polymer blend, PMMA has been recently used to improve the efficiency of electroluminescent devices. ${ }^{9}$ On the other hand, poly $(N$-vinyl carbazole) (PVCz) is an electroluminescent polymer, although the efficiency of its devices is very low. ${ }^{10,11}$ To improve the efficiency, PVCz must be blended with small organic molecules or with other polymers. ${ }^{12-15}$ When blended with PMMA, the devices combine the good optical quality of PMMA with the electroluminescent property of PVCz. However, as observed for other polymer blends, non-uniform topology is usually observed because of the poor miscibility between components. One possible approach to avoid these problems is to substitute some of the acrylate groups of PMMA with carbazolyl groups along the PMMA chains. Here, we report the synthesis and characterization of the photoluminescence of a PMMA-based polymer with appended carbazolyl groups.

Complex models are required to understand the photoluminescent properties of PVCz and other carbazolylbased polymers. The emission spectra frequently consist of overlapping bands from isolated lumophores $\left(\lambda_{\text {em }} c a .350 \mathrm{~nm}\right)$, excimers where only one ring of each aromatic moiety is overlapped $\left(\lambda_{\text {em }} c a .390 \mathrm{~nm}\right)$, excimers where both rings of each aromatic moiety are overlapped $\left(\lambda_{\text {em }} c a .440 \mathrm{~nm}\right)$ and phosphorescence at lower temperatures $\left(\lambda_{\text {em }} c a .440 \mathrm{~nm}\right) .^{11,16-28}$ The relative contributions of these species to the total emission intensity depend on the polymer tacticity, the polymer concentration in solutions, the type of solvent used to prepare the films, and temperature. ${ }^{26}$ Moreover, because the probability of formation of aggregated and excimeric species is higher in the solid state than in solution, the band profiles are different, and time-resolved fluorescence decays are multi-exponential in both states. ${ }^{20-32}$ The eventual emission depends on complex equilibria involving several carbazolyl groups, which, in turn, depends on temperature as it influences the equilibria, the relative importance of intrinsic radiative and non-radiative processes, and extrinsic polymer relaxation processes..$^{20,22,23,33-37}$

Here, we describe the synthesis and the chemical, photophysical and thermal characterization of a carbazolyl- based PMMA copolymer (PMMA-Cz) which has been prepared by exhaustive esterification of a commercially available copolymer, poly(methyl methacrylate-comethacrylic acid) (PMMA-co-PMAA). The photophysical properties of the PMMA-Cz are compared with those of the corresponding model compound, 9H-carbazole9-ethanol $(9 \mathrm{HCz})$. From steady-state and fluorescence lifetime measurements, carbazolyl moieties and their aggregates are identified as the emitting species in the PMMA-Cz films. Because the photophysical response of the carbazolyl fluorophore is affected by its interaction with its immediate microenvironment, the steady-state and dynamic luminescence data allow us to infer the nature of the chain motions that lead to the polymer relaxation processes. These studies also extend our use of luminescence from covalently-attached reporter groups to obtain detailed information about the onset or cessation of specific chain motions occurring over very small ( $c a$. one nanometer) regions of polymers that are structurally very different from PMMA. ${ }^{34,38-41}$

\section{Experimental}

\section{Carbazolyl-based polymer preparation}

At $273 \mathrm{~K}$ and under a dry atmosphere, $0.5 \mathrm{~mL}$ (3.44 mmol) of oxalyl chloride (Sigma-Aldrich) was added with stirring to a mixture of $2.0 \mathrm{~g}(0.058 \mathrm{mmol}$ of monomer) of 1.0:0.016 PMMA-co-PMAA (Sigma-Aldrich, $\mathrm{M}_{\mathrm{n}} c a .15 \mathrm{~kg} \mathrm{~mol}^{-1}$ and $\mathrm{M}_{\mathrm{w}} c a .34 \mathrm{~kg} \mathrm{~mol}^{-1}$, atactic) in $15 \mathrm{~mL}$ of dry chloroform (Sigma-Aldrich, HLPC grade) and $3.0 \mathrm{~mL}$ of dried (over Na) pyridine (Sigma-Aldrich). The mixture was stirred at $273 \mathrm{~K}$ for $4 \mathrm{~h}$, brought to room temperature, and solvent was removed by evaporation under dynamic vacuum for $24 \mathrm{~h}$. Then, $0.0741 \mathrm{~g}$ of $9 \mathrm{H}$-carbazole9-ethanol $(9 \mathrm{HCz}$ ) (Sigma-Aldrich, $98 \%$ pure) in $10 \mathrm{~mL}$ of chloroform was added and the solution was left for $24 \mathrm{~h}$ in a dry atmosphere. After removing the liquid under vacuum at room temperature, the residue was washed with $30 \mathrm{~mL}$ of aqueous, saturated sodium bicarbonate solution and dried over anhydrous magnesium sulfate (Merck, PA). The product was dissolved in chloroform and precipitated by adding ether (Merck, PA) eight consecutive times (Scheme 1); a final precipitation was effected with methanol and the product was dried under a dynamic vacuum for $6 h$.

Polymer films were cast from a chloroform solution onto Petri dishes which had been silanized with dichlorodimethylsilane (Merck, PA) to avoid adhesion. They were kept under dynamic vacuum for $48 \mathrm{~h}$ to ensure removal of the chloroform. The average thickness of the films, $0.16 \pm 0.02 \mathrm{~mm}$, based on 10 measurements taken 
<smiles>CCC(C)(CCCCC(C)(C)C(=O)O)C(=O)OC</smiles>

(1) +<smiles>OCCn1c2ccccc2c2ccccc21</smiles><smiles>O=C(Cl)C(=O)Cl</smiles>

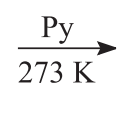<smiles>[Y1][CH]CC(C)(CCCC(C)(C)CC)C(=O)OC</smiles>

(1)<smiles>[Y][Al]CCC(C)(CCC(C)(C)CC)C(=O)OCCn1c2ccccc2c2ccccc21</smiles>

Scheme 1. Procedure for the preparation of carbazolyl-based PMMA-Cz. Py $=$ pyridine. $\mathbf{x}$ (the mole fraction of carbazoyl groups in the polymer) $=0.016$ is based on the assumption that all of the acid groups of the PMMA-co-MAA are esterified in PMMA-Cz (see text).

at different places on the surfaces, was measured with a Mitutoyo digital micrometer. In order to compare the thermal and photophysical properties, parts of the same polymer film were used for each type of experiment. Thus, different measurements were performed with material having the same previous history.

\section{Methods}

The PMMA-Cz in $\mathrm{KBr}$ disks was characterized by FT-IR spectroscopy; spectra are the average of 16 scans from a Bomem B 100 FTIR spectrophotometer in the spectral range of $600-4000 \mathrm{~cm}^{-1}$ and with $2 \mathrm{~cm}^{-1}$ resolution. UV/Vis absorption spectra were recorded using a dualbeam Perkin-Elmer Lambda-6 spectrophotometer. The molar contents of the carbazolyl moieties were determined spectrophotometricaly by building a calibration curve from standard solutions of $9 \mathrm{HCz}$ in chloroform (with molar concentrations ranging from $5 \times 10^{-7}$ to $1 \times 10^{-4} \mathrm{~mol} \mathrm{~L}^{-1}$ ) and then measuring the absorbance of polymer samples in chloroform solution. Using the molar absorptivity coefficient of carbazolyl units at absorption wavelength of $332 \mathrm{~nm}$ as $0.401 \mathrm{~L} \mathrm{~mol}^{-1} \mathrm{~cm}^{-1}$, we found the molar amount of carbazolyl as $4.91 \times 10^{-5} \mathrm{~mol} \mathrm{~L}^{-1}$.

The glass transition was located by differential scanning calorimetry (DSC) using a Perkin Elmer DSC-7 series calorimeter calibrated with indium metal. The heatingcooling sequence was as follows: heat from 130 to $470 \mathrm{~K}$ at
$10 \mathrm{deg} \mathrm{min}^{-1}$; cool from $470 \mathrm{~K}$ to $130 \mathrm{~K}$ at $20 \mathrm{deg} \mathrm{min}^{-1}$. A separate sample was initially cooled from room temperature to $130 \mathrm{~K}$ at $20 \mathrm{deg} \mathrm{min}^{-1}$.

Dynamical mechanical thermal analyses (DMTA) of films were performed in a Rheometric Scientific DMTA-V dynamic mechanic analyzer (Piscataway, NJ), operating at a $1 \mathrm{~Hz}$ oscillation rate, amplitude of deformation of $0.02 \%$ and with a heating rate of $3 \mathrm{deg} \mathrm{min}^{-1}$ from 160 to $460 \mathrm{~K}$.

Steady-state fluorescence spectra were recorded in an ISS-PCI spectrofluorimeter, operating with a $300 \mathrm{~W}$ Xe arc lamp using $1 \mathrm{~cm}$ square quartz cuvette for $\mathrm{N}_{2}$-saturated solutions and a homemade holder for films. Phosphorescence spectra of $\mathrm{N}_{2}$-saturated solutions and of films were recorded in sealed quartz vessels with a F-4500 Hitachi Spectrofluorimeter using a $300 \mathrm{~W}$ pulsed Xenon lamp. Spectra at room temperature and $77 \mathrm{~K}$ were recorded.

Dynamic fluorescence measurements were performed in an Edinburgh Analytical nF900 time-correlated singlephoton counting apparatus using a pulsed hydrogen lamp at a repetition rate of $40 \mathrm{kHz}$. The instrument response was determined using Ludox ${ }^{\circledR}$ as scatterer. Reconvolution of the lamp pulse and sample signal was performed as described elsewhere. ${ }^{41}$ Decay histograms of $\mathrm{N}_{2}$-saturated solutions in sealed $1 \mathrm{~cm}$ quartz cuvettes were obtained in a front-face configuration. Solid-state samples were sealed under vacuum in quartz tubes and aligned at a $c a .45^{\circ}$ angle with respect to the incident radiation and the emission 
was collected at a right-angle from the back face. Timeresolved fluorescence spectra (TRES) were also constructed from 'time slices' of decay curves recorded at intervals of $10 \mathrm{~nm}$, in the range of 340 to $460 \mathrm{~nm}$ and with excitation at $300 \mathrm{~nm}$.

Emission spectra of films, held between two quartz windows and maintained under dynamic vacuum at $10^{-4}$ Torr, were recorded from 30 to $410 \mathrm{~K}$ at 10 degree intervals in a cryostat described elsewhere. ${ }^{34-37}$

\section{Results and Discussion}

\section{Polymer characterization}

From the DSC thermogram for PMMA-Cz (Figure 1a) and using the conventional method of tangent lines, we determined the glass transition as $380 \mathrm{~K}$, a value higher than observed for PMMA and lower than that reported for poly(methacrylic acid). ${ }^{35,36,42-46}$ This value is very similar to that of the pristine material given by the supplier which is $378 \mathrm{~K}$.

PMMA-Cz also shows a weaker secondary relaxation process at $320 \mathrm{~K}$, in addition to the glass transition at $380 \mathrm{~K}$, by both the loss and storage moduli in the DMTA traces (Figure 1b,c) as well as by $\tan \delta$ (Figure 1d). A similar sub-glass process $(\mathrm{T}=320 \mathrm{~K})$, which has been
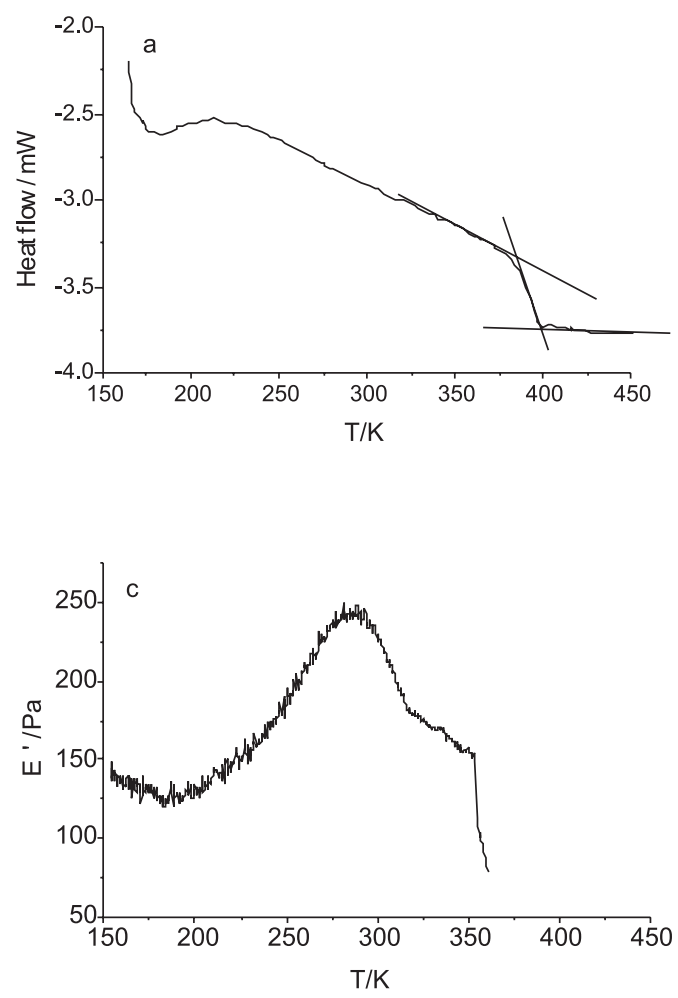

attributed to the $\beta$-relaxation process involving sidechain motions of the ester groups, has also been observed for poly(methylmethacrylate-co-methylanthracenyl methacrylate) near $280 \mathrm{~K} .{ }^{35}$ In general, the highest temperature thermal induced relaxation process for PMMA $(\mathrm{T}=380 \mathrm{~K})$, the $\alpha$-relaxation, is associated with the glass transition, and involves long-range conformational changes of the polymer chain..$^{35,36,43}$ This result is in agreement with the reported dynamical-mechanical relaxation processes of PMMA. ${ }^{40}$ Additional evidence for the source of these relaxation processes will be provided by the fluorescence emission data (vide infra).

FTIR spectra of PMMA-Cz were compared with those of PMMA-co-MAA and $9 \mathrm{HCz}$. The spectrum of the derivatized film exhibits a new band at $1434 \mathrm{~cm}^{-1}(\mathrm{C}=\mathrm{N}$ stretching mode) (Figure S1 - Supplementary information). These results indicate that the transformation of PMMA-coMAA to PMMA-Cz was successful, at least qualitatively.

Additional proof for the attachment of carbazolyl groups to the free acid sites of PMMA-co-MAA is provided by changes in the emission spectra of $\mathrm{N}_{2}$-saturated solutions of PMMA-Cz in chloroform upon addition of aliquots of the base, pyridine. Fluorescence from pendant carbazolyl groups is known to be quenched by acids and shifted in wavelength upon $\mathrm{pH}$ changes. ${ }^{47}$ Therefore, if some acidic groups had remained along the polymer chain and were
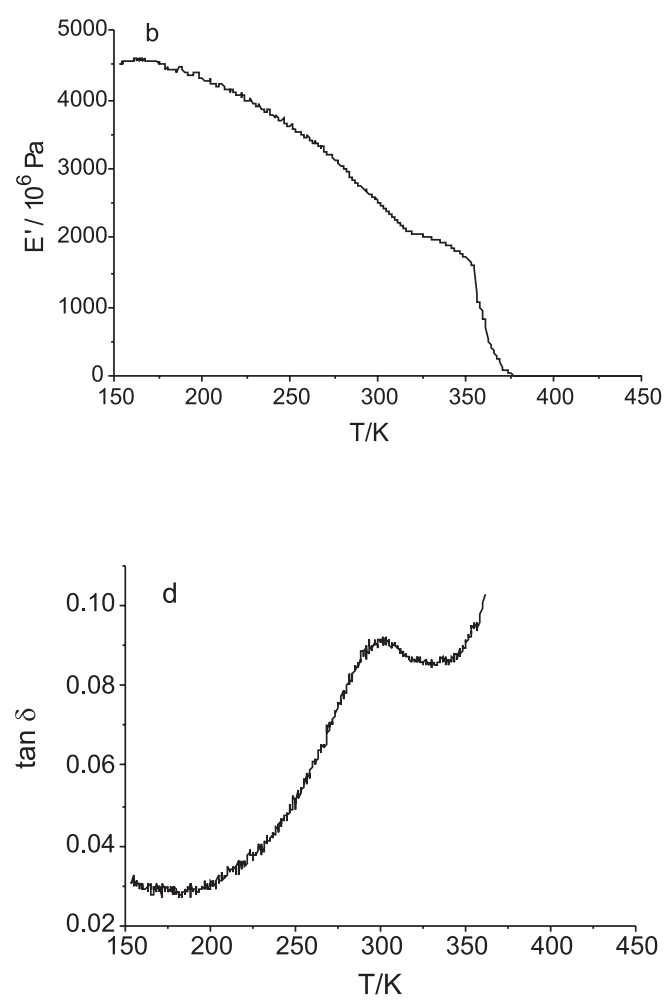

Figure 1. (a) DSC thermograms (heating rate $10 \mathrm{deg} \mathrm{min}^{-1}$ ) and DMTA measurements (1 Hz, heating rate 3 deg $\mathrm{min}^{-1}$ ) from 120 to $400 \mathrm{~K}$; (b) storage modulus ( $\left.E^{\prime}\right)$; (c) loss modulus ( $\left.E^{\prime \prime}\right)$ and (d) $\tan \delta$ versus temperature for a PMMA-Cz film. 
near carbazolyl groups, the intensity of the emissions from PMMA-co-MAA should have increased upon addition of aliquots of pyridine. Spectral shifts, but no quenching, were discernible when $0.1,0.5,1,2,3,4$ and $5 \mathrm{~mL}$ aliquots of pyridine were added sequentially to $15 \mathrm{~mL}$ of a PMMA-Cz in chloroform solution. The lack of fluorescence quenching demonstrates that either the acidic groups are completely esterified or are in concentration too low to influence the photophysical properties of the carbazolyl groups during their excited state lifetimes.

Steady-state excitation and fluorescence spectra for $10^{-6} \mathrm{~mol} \mathrm{~L}^{-1} 9 \mathrm{HCz}$ (a model compound for the carbazolyl groups in PMMA-Cz) in $\mathrm{N}_{2}$-saturated chloroform solutions (Figure 2) are mirror images, with a Stokes shift of $766 \mathrm{~cm}^{-1}$. The relative intensity of the $0-0$ band of the emission spectrum at $354 \mathrm{~nm}$ in a more concentrated solution $\left(10^{-3} \mathrm{~mol} \mathrm{~L}^{-1}\right)$ is attenuated as a result of self-absorption effects. No emission attributable to an excimer was detected in the chloroform solutions.

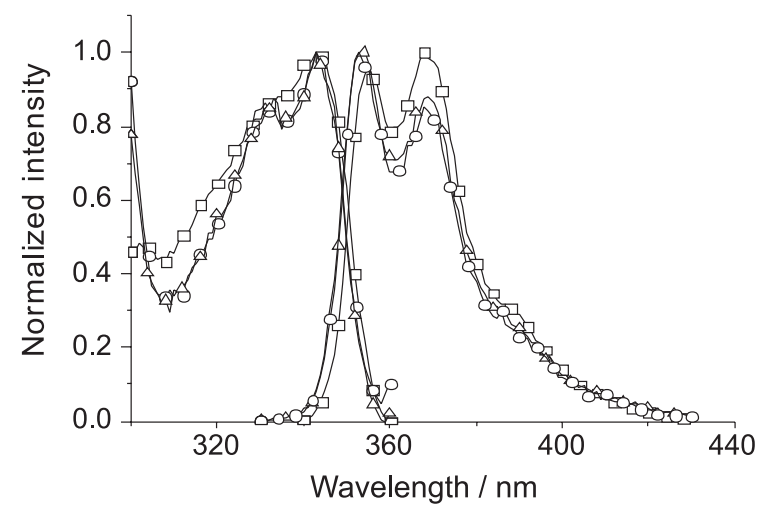

Figure 2. Steady-state excitation $\left(\lambda_{\text {em }}=360 \mathrm{~nm}\right)$ and fluorescence $\left(\lambda_{\text {exc }}=295 \mathrm{~nm}\right)$ spectra of $9 \mathrm{HCz}$ in $\mathrm{N}_{2}$-saturated chloroform solutions: $10^{-6} \mathrm{~mol} \mathrm{~L}^{-1}(-\Delta-\Delta-), 10^{-5} \mathrm{~mol} \mathrm{~L}^{-1}\left(-O_{-} \mathrm{O}_{-}\right)$and $10^{-3} \mathrm{~mol} \mathrm{~L}^{-1}$ (- $\left.\square-\square-\right)$ at room temperature.

The excitation and fluorescence spectra of PMMA-Cz in chloroform solution are mirror images, also, and their vibronic progressions, $1670-1690 \mathrm{~cm}^{-1}$, are very similar to that of $9 \mathrm{HCz}$ (Figure 3). The 0-0 excitation and emission bands for PMMA-Cz are centered at 342 and $347 \mathrm{~nm}$, respectively; both are blue-shifted with respect to the bands of $9 \mathrm{HCz}$ at 344 and $359 \mathrm{~nm}$. The small Stokes shift, $c a .420 \mathrm{~cm}^{-1}$, indicates that a very small change of carbazolyl geometry or solvation occurs upon excitation in the polymer. The low intrachain concentration of attached carbazolyl groups in the PMMA-Cz polymer is responsible for the high relative intensity of its $0-0$ emission band. Again, no excimer emission has been observed even for more concentrated solutions. The absence of excimer emission indicates that the carbazolyl moieties are not in the vicinity of each other.

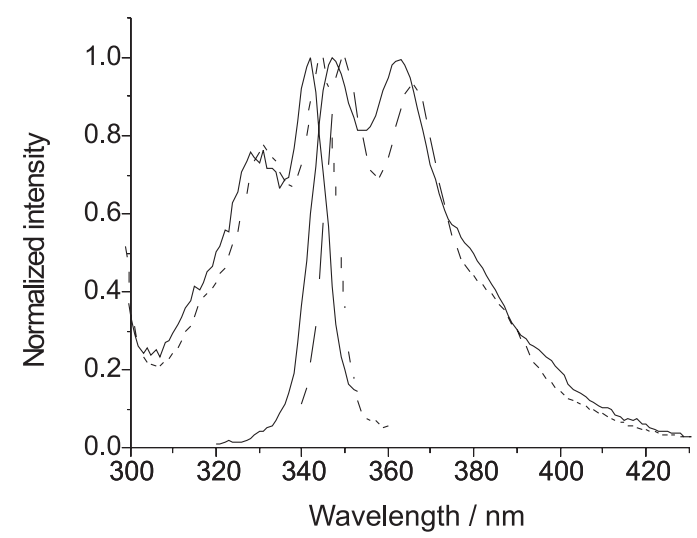

Figure 3. Steady-state excitation $\left(\lambda_{\text {em }}=350 \mathrm{~nm}\right)$ and fluorescence spectra $\left(\lambda_{\text {exc }}=295 \mathrm{~nm}\right)$ of $10^{-5} \mathrm{~mol} \mathrm{~L}^{-1} 9 \mathrm{HCz}(--)$ and $0.02 \mathrm{~g} \mathrm{~L}^{-1} \mathrm{PMMA}-\mathrm{Cz}(-)$, both in $\mathrm{N}_{2}$-saturated chloroform at room temperature.

Static and dynamic photophysical measurements of PMMACz films

The excitation and emission spectra of PMMA-Cz films at room temperature are also mirror images, but blueshifted by $3 \mathrm{~nm}$ in comparison with the solution spectra; the Stokes shift of the film is $247 \mathrm{~cm}^{-1}$. A protracted, red-edge tail in the emission spectrum is attributed to the presence of aggregates (excimers or excitation of ground-state dimers) (Figure is not included). The vibronic structure in the emission spectrum of the film is also similar to that of the solution, although the former is broader due to both inhomogeneous broadening (usually observed in the solid state) and conformational disorder (always present in polymer chains of amorphous solids)..$^{34,35}$

Care was taken to maintain the same instrumental parameters and same position for each PMMA-Cz film throughout the collection of a data set (i.e., over the whole temperature range) to allow comparison of emission intensities (between 330 and $500 \mathrm{~nm} ; \lambda_{\text {exc }}=295 \mathrm{~nm}$ ) from steady-state fluorescence spectra recorded at different temperatures (from 30 to $410 \mathrm{~K}$ at intervals of 10 degree) (Figure 4). The information available from this experiment is illustrated by comparing spectra at 80 and $300 \mathrm{~K}$. Although the overall spectral shape at $300 \mathrm{~K}$ is very similar to that in solution (Figure 3), the $0-0$ band at $347 \mathrm{~nm}$ is followed by other vibronic bands at 367 and $385 \mathrm{~nm}$ and a red-edge tail from $390 \mathrm{~nm}$ to $480 \mathrm{~nm}$. As in the case of solutions of the polymer and the model lumophore, the structured higherenergy vibronic band was assigned to the emission from isolated carbazolyl groups. The emission spectrum at $80 \mathrm{~K}$ is more complex, exhibiting bands at $347 \mathrm{~nm}$ and $367 \mathrm{~nm}$ from the isolated lumophores ${ }^{22,24-26,31,48,49}$ which were very slightly hypsochromically shifted and markedly less intense relative to the red-edge emission at $400-460 \mathrm{~nm}$. The rededge emission may be from the excitation of ground-state 
aggregates, to excimers, ${ }^{18,20,25-27,29,32}$ or to phosphorescence. ${ }^{48}$ However, because excimer emission is always unstructured and this region is not, at least a part of it must be attributed to another form of emitting species.

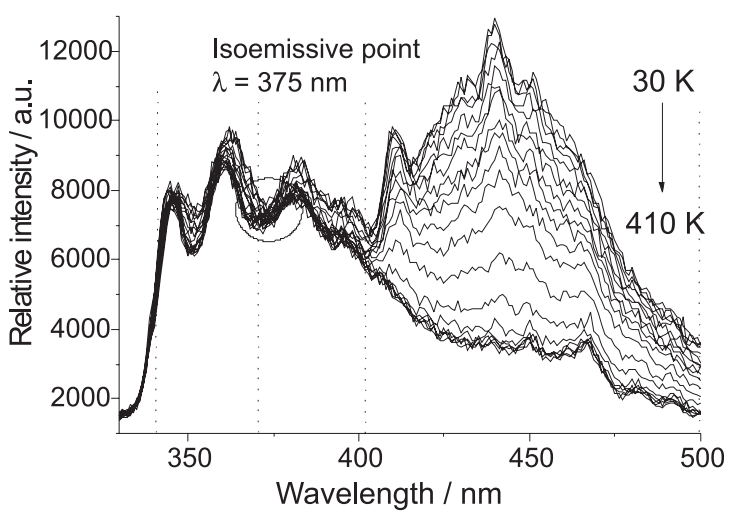

Figure 4. Steady-state emission spectra obtained for a PMMA-Cz film in the range of 30 to $410 \mathrm{~K}$ at intervals of $10 \mathrm{~K}$. $\lambda_{\mathrm{ex}}=295 \mathrm{~nm}$.

To obtain additional information about the origin of the broad, lower-energy emission band of PMMA-Cz, emission spectra were recorded under steady-state conditions at $77 \mathrm{~K}$ while incrementally changing the excitation wavelength from 290 to $346 \mathrm{~nm}$ (Figure 5). Spectra in this figure are scaled using band 1 at $\lambda_{\text {em }}=343 \mathrm{~nm}$ for comparison. These experiments allow molecules in different sites to be excited selectively and their different emission characteristics to be distinguished. Isolated lumophores are preferentially excited by radiation at the blue-edge of the lowest energy absorption $\left(\lambda_{\text {exc }}=290-300 \mathrm{~nm}\right)$. The resulting emission spectra have an emission centered at $350 \mathrm{~nm}$ whose relative intensity is higher than the band centered at $450 \mathrm{~nm}$. Excitation at the red-edge $\left(\lambda_{\text {exc }}=320-346 \mathrm{~nm}\right)$ results in emissions in which the lower energy emission band at $450 \mathrm{~nm}$ is more intense than the higher energy band. The evolution of the emission intensity ratio, $\mathrm{I}_{440} / \mathrm{I}_{360}$, increases from 1.41 to 1.64 to 1.67 as the excitation wavelength is changed from 295 to 310 to $320 \mathrm{~nm}$. Thus, when $\lambda_{\text {exc }}>300 \mathrm{~nm}$, emission from aggregated species becomes more intense. This result clearly demonstrates that at least a part of the $440 \mathrm{~nm}$ band emission is from ground state aggregates.

Additionally, spectra and decays for degassed systems were recorded using millisecond time-resolved spectroscopy at both room temperature and $77 \mathrm{~K}$ (Figure 6). At room temperature, emissions attributable only to fluorescence of the isolated lumophores and aggregates could be detected. However, at $77 \mathrm{~K}$, two overlapping emission bands in the aggregate region $(400-550 \mathrm{~nm})$ could be discerned in addition to the emission from isolated lumophores. The two components

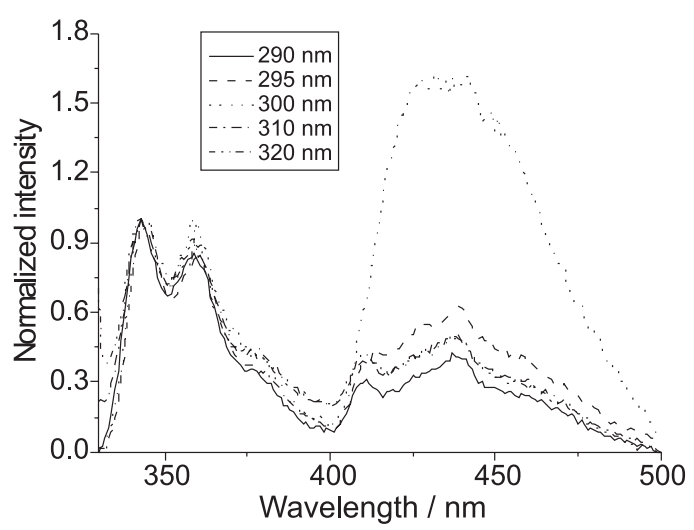

Figure 5. Scaled steady-state emission spectra of a PMMA-Cz film at $77 \mathrm{~K}$ at several excitation wavelengths.

of the 400-450 nm band are attributed to fluorescence of aggregated carbazolyl groups and to phosphorescence (lower intensity), probably from isolated carbazolyl groups. The lifetime associated with the monoexponential phosphorescence decay collected at $\lambda_{\mathrm{em}}=440 \mathrm{~nm}, 1.2 \mathrm{~s}$, is in agreement with reported values for similar species. ${ }^{16,20}$ Also, the spectra in Figure 5 show a valley from 380 to $400 \mathrm{~nm}$ that is not present in the spectra recorded at room temperature. One possible source of this emission may be a more energetic excimer whose conformation is dictated by its local environment. The millisecond time-resolved spectra demonstrate that phosphorescence makes a negligible contribution to the total luminescence at room temperature, although it is apparent (albeit still weakly) at $77 \mathrm{~K}$.

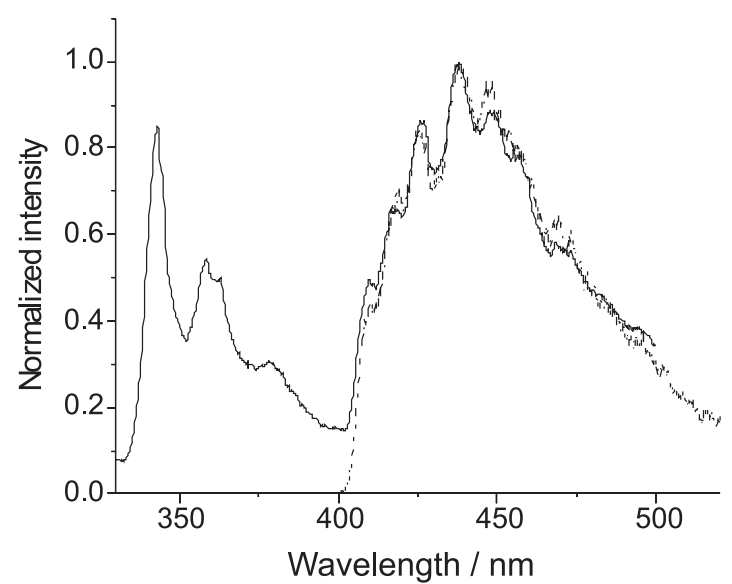

Figure 6. Steady-state (-) and millisecond time-resolved emission (i.e., phosphorescence, ----) (intensity $\times 10$ ) spectra of a PMMA-Cz film both taken at $77 \mathrm{~K}$.

Decay curves from nanosecond time-correlated single photon counting experiments at room temperature and degassed systems using $\lambda_{\text {exc }}=295 \mathrm{~nm}$ and $\lambda_{\mathrm{em}}=350 \mathrm{~nm}$ (i.e., where the isolated carbazolyl groups emit) can be fitted satisfactorily by a biexponential function in which the decay 
constants are $12 \mathrm{~ns}$ (larger amplitude) and 3-4 ns (smaller amplitude) (Table 1) (Figure S2 a,b - Supplementary Information). Although both decay components are thought to be from the emission of isolated carbazolyl groups, the longer one is attributed to that fraction which is truly isolated during its excited singlet lifetime and the shorter one to groups which encounter another (groundstate) carbazolyl during their excited singlet lifetime and, therefore, are dynamically quenched. ${ }^{24,31,43,47}$ Evidence for the independent dynamics of these two populations comes from the observation that neither has a protracted rise time (i.e., both sets of excited singlet states appear to be formed within the duration of the lamp pulses of the instrument). When the decay curves were collected at $367 \mathrm{~nm}$, both components were observed but the amplitude of the faster was enhanced.

The fluorescence decays from aggregates, recorded using $\lambda_{\text {exc }}=345 \mathrm{~nm}$ and $\lambda_{\mathrm{em}}=430 \mathrm{~nm}$, were monoexponential at room temperature and biexponential at $77 \mathrm{~K}$ (Figure S2 c,d -Supplementary Information) suggesting that one aggregate species (or several which are able to equilibrate structurally much faster than they emit) is present at room temperature, whereas two general types of aggregates are frozen into their structures for periods significantly longer than their excited state lifetimes at the lower temperature. Phosphorescence, which is detectable at $77 \mathrm{~K}$, does not contribute noticeably to the TCSPC decay curves because the vast majority of it occurs outside the short time window of collection for the fluorescence.

Nanosecond, time-resolved emission spectra (TRES) at $77 \mathrm{~K}$ were recorded in the spectral range from $\lambda_{\mathrm{em}}=340$ to $460 \mathrm{~nm}$ at increments of $10 \mathrm{~nm}$ (Figure 7). A global analysis of the decay curves at $\lambda_{\mathrm{em}}=340-370 \mathrm{~nm}$ results in a mono-exponential profile with a decay constant of $12 \mathrm{~ns}$. The spectral profiles are similar to the steady-state emission spectra of the isolated carbazolyl groups, but lack their spectral resolution. By contrast, the decays for emissions from 380 to $390 \mathrm{~nm}$ are bi-exponentials with a small (ca. $10 \%$ ) contribution of a shorter decay constant (4 ns). The contribution of this component increases to $20 \%$ from $\lambda_{\mathrm{em}}=410$ to $440 \mathrm{~nm}$, and to $40 \%$ at $\lambda_{\mathrm{em}}=450 \mathrm{~nm}$; at longer emission wavelengths, the decay curves could not be fitted satisfactorily using functions with one to four exponentials. These data are in agreement with the conclusions from our steady-state emission spectra obtained at different excitation wavelengths (Figure 5): distinct aggregated species contribute to the emission spectra.
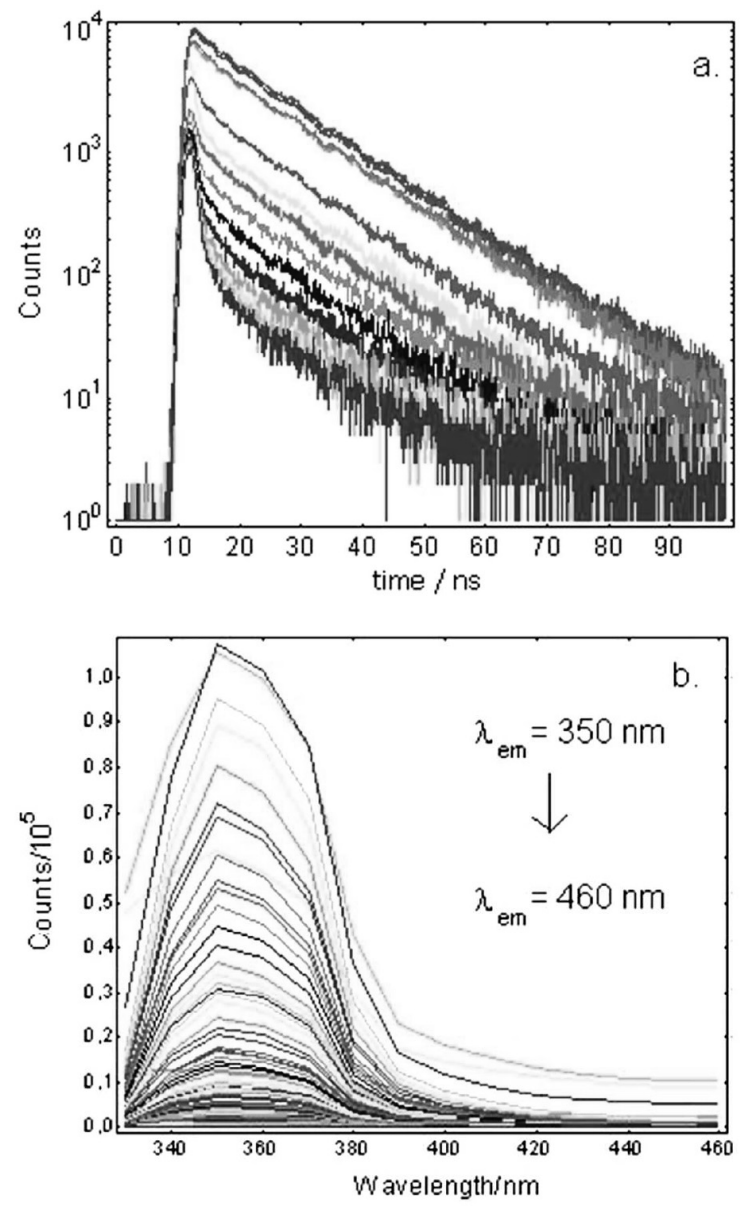

Figure 7. (a) Fluorescence decays $\left(\lambda_{\mathrm{em}}=350\right.$ to $460 \mathrm{~nm}$, collected at intervals of $10 \mathrm{~nm}$ ) and (b) nanosecond time-resolved fluorescence spectra of a PMMA-Cz films at 77 K. $\lambda_{\text {exc }}=295 \mathrm{~nm}$.

Table 1. Fluorescence decay constants (ns) of PMMA-Cz films at room temperature and $77 \mathrm{~K}$ collected at different emission wavelengths. ${ }^{a} \lambda_{\text {exc }}=295 \mathrm{~nm}$ unless indicated otherwise

\begin{tabular}{|c|c|c|c|c|c|c|}
\hline \multirow{2}{*}{$\lambda_{\mathrm{em}} /(\mathrm{nm})$} & \multicolumn{3}{|c|}{ Room temperature } & \multicolumn{3}{|c|}{$77 \mathrm{~K}$} \\
\hline & $\tau_{1} /(\mathrm{ns})$ & $\tau_{2} /(\mathrm{ns})$ & $\chi^{2 \mathrm{c}}$ & $\tau_{1} /(\mathrm{ns})$ & $\tau_{2} /(\mathrm{ns})$ & $\chi^{2 \mathrm{c}}$ \\
\hline 350 & $12.21 \pm 0.02(94 \%)$ & $3.53 \pm 0.05(6 \%)$ & 1.295 & $12.23 \pm 0.05(94 \%)$ & $2.72 \pm 0.08(6 \%)$ & 1.177 \\
\hline 367 & $13.36 \pm 0.07(80 \%)$ & $7.4 \pm 0.2(20 \%)$ & 1.164 & $12.64 \pm 0.08(94 \%)$ & $3.6 \pm 0.1(6 \%)$ & 1.171 \\
\hline $430^{\mathrm{b}}$ & $4.0 \pm 0.1(100 \%)$ & --------- & 1.231 & $9.7 \pm 0.3(56 \%)$ & $2.1 \pm 0.2(44 \%)$ & 1.219 \\
\hline
\end{tabular}

${ }^{a}$ Values in parentheses are the relative contributions of each component. Contributions from scatter were subtracted empirically. Differences from $100 \%$ are due to the scattering component; ${ }^{\mathrm{b}} \lambda_{\mathrm{exc}}=345 \mathrm{~nm}$. ${ }^{\mathrm{c}}$ The $\chi^{2}$ values are for fits to biexponential functions except for the data set at room temperature and $\lambda_{\mathrm{em}}=430 \mathrm{~nm}$. 
Temperature effects on steady-state fluorescence spectra of PMMA-Cz films

As discussed above, fluorescence spectra recorded from 30 to $410 \mathrm{~K}$ (Figure 4) are comprised of emissions from several different species: isolated lumophores (M) emitting at $\mathrm{h} v_{\mathrm{FM}}=340-390 \mathrm{~nm}$; excited singlet states of dimers $(\mathrm{D} *)$ and excimers (E) whose emissions $\left(\mathrm{h} v_{\mathrm{FD}}\right.$ and $\mathrm{h} v_{\mathrm{E}}$, respectively) at 420-500 nm overlap the phosphorescence of isolated lumophores in their triplet states $\left({ }^{3} \mathrm{M}^{*}\right)$ (Scheme 2). The relative contribution of each species depends differently on temperature. The rate constants for non-radiative decay of the isolated lumophores $\left(\mathrm{k}_{\mathrm{nr}(\mathrm{M})}\right)$, the equilibrium population of the ground-state aggregates $\left(\mathrm{k}_{\mathrm{nr}(\mathrm{D})}\right)$, and the kinetics of encounter $\left(\mathrm{k}_{\mathrm{a}}\right)$ and dissociation $\left(\mathrm{k}_{\mathrm{d}}\right)$ by the dynamically formed excimers are reasonably expected to have different Arrhenius behaviors. In addition, the rates of intersystem crossing $\left(\mathrm{k}_{\mathrm{ISC}(\mathrm{M})}\right)$, and phosphorescence from the excited triplet states should follow yet another temperature dependence. Finally, each of these dependencies is coupled, to a greater or lesser extent, to the temperature dependence of the motions and state of the PMMA matrix. Because of this complexity, only qualitative analyses of the temperature dependence of the contributions of each emitting species to the total luminescence were attempted. To do so, the entire emission spectrum was divided into two parts as shown in Figure 4 and the spectral intensity of each (as an integrated area) was plotted: one part is where isolated carbazolyl groups are the dominant emitting species (340-370 nm; Figure 8a) and the other is where the fluorescence from aggregates (ground state dimers and excimers) and phosphorescence from isolated carbazolyl groups are found $(420-500 \mathrm{~nm}$; Figure 8b).

The integrated intensity in the range, $340 \mathrm{~nm}>\lambda_{\mathrm{em}}>$ $370 \mathrm{~nm}$, is almost constant from 30 to $130 \mathrm{~K}$; from 130 to $310 \mathrm{~K}$ the intensity increases and for $\mathrm{T}>310 \mathrm{~K}$, the intensity becomes constant again. There is an isoemissive point at $375 \mathrm{~nm}$ (Figure 4). Usually, the fluorescence intensity decreases with increasing temperature because the rate constants for non-radiative deactivation increase more rapidly with temperature than do those for radiative processes. ${ }^{33}$ Therefore, the increase of intensity above $130 \mathrm{~K}$ and the presence of an isoemissive point at the red-edge of the emission band for the isolated lumophores suggest that another species, emitting at lower energy, can be converted in a thermally activated process to the singlet excited state of the isolated carbazolyl groups. Moreover, considering that the fluorescence intensity at $340-370 \mathrm{~nm}$ increases between $c a .130$ and $300 \mathrm{~K}$, we suggest that this species is a partially overlapping (higher energy) excimer. ${ }^{29,47-49}$
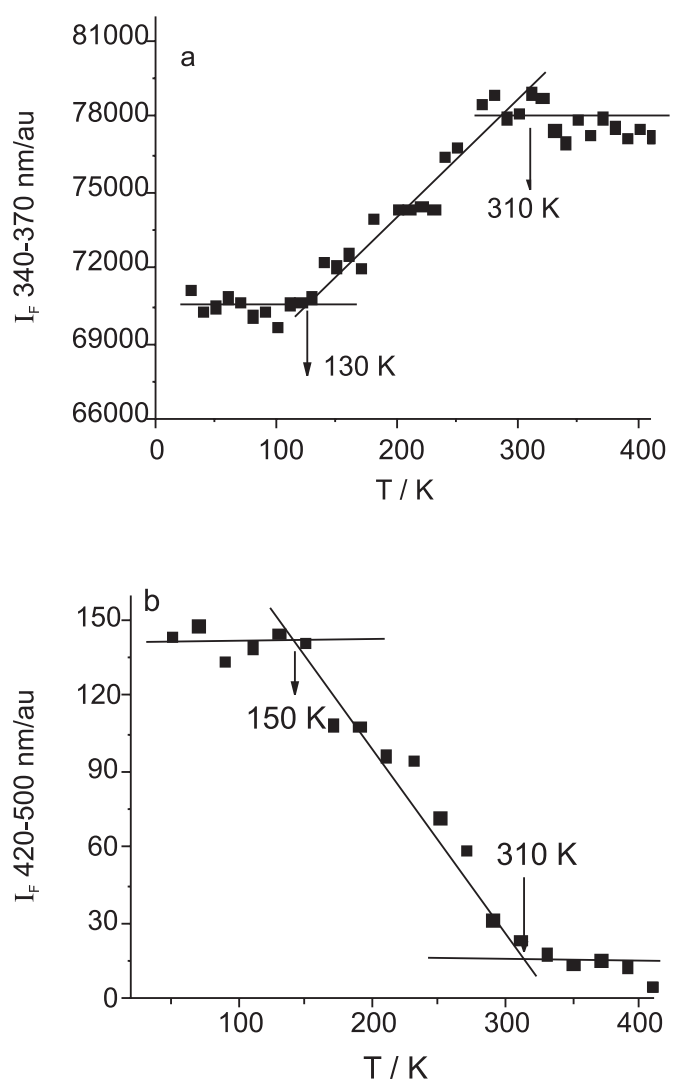

Figure 8. Integrated intensity of emission $\left(I_{F}\right)$ of PMMA-Cz films versus temperature (spectra in Figure 5) for (a) $\lambda_{\text {em }}=340-370 \mathrm{~nm}$ and (b) $\lambda_{\text {em }}=420-500 \mathrm{~nm}$. Lines are drawn empirically; they are included to visualize the slopes and to locate the intersection temperatures representing the abrupt slope changes.
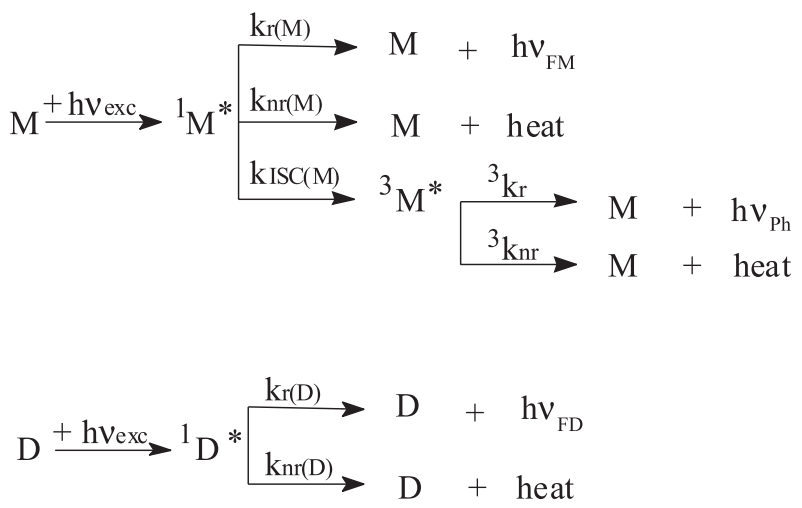

${ }^{1} \mathrm{M}^{*}+\mathrm{M} \underset{\mathrm{kd}}{\stackrel{\mathrm{ka}}{\rightleftharpoons}} \mathrm{E} \stackrel{\mathrm{kr}(\mathrm{E})}{\longrightarrow} 2 \mathrm{M}+\mathrm{h} \mathrm{E}_{\mathrm{E}}$

Scheme 2. Kinetic diagram for the interconversion between emissive species of PMMA-Cz film. $\mathrm{hv}_{\mathrm{ex}}$ is the excitation energy $\left(\lambda_{\mathrm{ex}}=350 \mathrm{~nm}\right)$; $\mathrm{M}$ is an isolated carbazolyl moiety with emission at $\mathrm{hv}$ $\mathrm{D}$ is a ground state dimer with emission at $\mathrm{h} v_{\mathrm{FD}}=440-550 \mathrm{~nm}$; $\mathrm{E}$ is a lower-energy excimer with emission at $h v_{\mathrm{E}}=440-550 \mathrm{~nm}$; h $v_{\mathrm{Ph}}$ is the phosphorescence emission at $440-550 \mathrm{~nm} ; \mathrm{k}_{\mathrm{r}}, \mathrm{k}_{\mathrm{nr}}$ and $\mathrm{k}_{\mathrm{ISC}}$ are the rate constants for radiative decay, non-radiative decay, and intersystem crossing, respectively. 
This bilumophoric process, excimer dissociation, is favored entropically as temperature increases and appears to offset the decreased quantum efficiency of fluorescence from isolated lumophores caused by the increase of radiationless rate constants (a unilumophoric process). The integrated intensity of the emission band covering 420-500 nm exhibits an opposite temperature dependence: it is almost constant from $c a .30$ to $150 \mathrm{~K}$, decreases from ca. 150 to $310 \mathrm{~K}$, and is approximately constant thereafter (Figure 8b). Therefore, the system undergoes significant changes which are sensed by the photophysical behavior of its excited state species at $130-150 \mathrm{~K}$ and $300-310 \mathrm{~K}$. The photophysical changes observed in the lower temperature regimes over the ranges of emission wavelengths ascribed to isolated and aggregated groups represented by the increase of the intensity of the isolate molecule and by the decrease of the lower energy excimer emission intensity are not completely complimentary and cannot be related exclusively to processes involving the interconversion of isolated and aggregated species because of the varying contribution from phosphorescence within the higher wavelength region. In other words, the magnitude of the decrease of the fluorescence intensity of the excimer in the range between 420 and $500 \mathrm{~nm}$ band is smaller than the increase of the emission intensity in the range 340-370 $\mathrm{nm}$.

The aforementioned involvement of a higher energy excimer, emitting near $390 \mathrm{~nm}$, was based upon the presence of a valley between the higher and lower energy bands in millisecond time-resolved spectra (Figure 5) and its absence in steady-state spectra (Figure 4). Several reports have invoked a PVCz excimer of this type; in the suggested geometry, only one aromatic ring of each aromatic moiety is overlapped. . $5,27,29,31$ As expected, emission from both excimer types is attenuated by higher temperatures.

In conclusion, the temperature dependence of the emission spectra and from the photophysical behavior observed by site-selective and time-resolved spectroscopy on the millisecond and nanosecond time scales is consistent with the simplified mechanistic steps shown in Scheme 2. Accordingly, absorption of incident radiation by the isolated (M) and ground-state aggregate (D) species produces ${ }^{1} \mathrm{M}^{*}$ and ${ }^{1} \mathrm{D}^{*}$, respectively, in amounts controlled by the products of their molar extinction coefficients and concentrations (i.e., by Beer's Law); it is reasonable to assume that the molar extinction coefficient of $\mathrm{D}$ is twice that of $\mathrm{M}$ at each wavelength. The excited state species undergo several photophysical processes, the most important of which is determined in large part by temperature. Since formation and dissociation of the excimers depend on chain movements (i.e., various modes of local diffusion), temperature is involved in more than the modulation of intermolecular events. Thus, assuming no dissociation of the excited ground state dimers, ${ }^{1} \mathrm{D}^{*}$, during their lifetime, the activation energy for the thermally induced dissociation of the lower energy excimer (the $k_{d}$ step in Scheme 2) can be estimated from an Arrhenius plot of the fluorescence intensity ratios, $\ln \left(\mathrm{I}_{\mathrm{M}} / \mathrm{I}_{\mathrm{E}}\right),{ }^{33}$ where $\mathrm{I}_{\mathrm{M}}$ and $\mathrm{I}_{\mathrm{E}}$ are the fluorescence intensities at 345 and $440 \mathrm{~nm}$ of the monomer and the sandwich-like lower energy excimer, respectively (Figure 9). The calculated value, $6.7 \mathrm{~kJ} \mathrm{~mol}^{-1}$, is consistent with other values for sandwich/monomer conversions $\left(6-8 \mathrm{~kJ} \mathrm{~mol}^{-1}\right) .26,49$ Although interconversion between the higher energy excimer and lower energy excimer is probably occurring (process not shown in Scheme 2), we assume that its rate constant is slower than the formation of monomer by the dissociation of both excimer forms (represented in the Scheme 2 by $\mathrm{k}_{\mathrm{d}}$ ). The reason for this assumption is that the relative motion of the carbazolyl moieties from the higher-energy to the lower-energy excimer is not only directionally well defined--the motion must be parallel to the ring planes--but it also involves relatively small distances, on the order of the dimension of one carbazolyl ring. On the other hand, the dissociation of the lower- or higher-energy type of excimer, resulting in an isolated excited-state species, should involve either or a combination of short distance translational or rotational motions that remove the coplanarity of the two ring systems or increase their interplanar distance. This leads to an additional assumption that temperature-dependent rate constants, $\mathrm{k}_{\mathrm{a}}$ and $\mathrm{k}_{\mathrm{d}}$, are also much lower in magnitude than those of the temperature-independent deactivation processes of both excimers, $\mathrm{k}_{\mathrm{nr}(\mathrm{D})}$ and $\mathrm{k}_{\mathrm{r}(\mathrm{D}))^{26,30}}$

Since the photophysical processes are extrinsically disturbed by the polymer chain motions, we also compared the temperature dependence of these processes with measurements of the thermal of induced relaxation processes of PMMA-Cz films by DSC and DMTA.

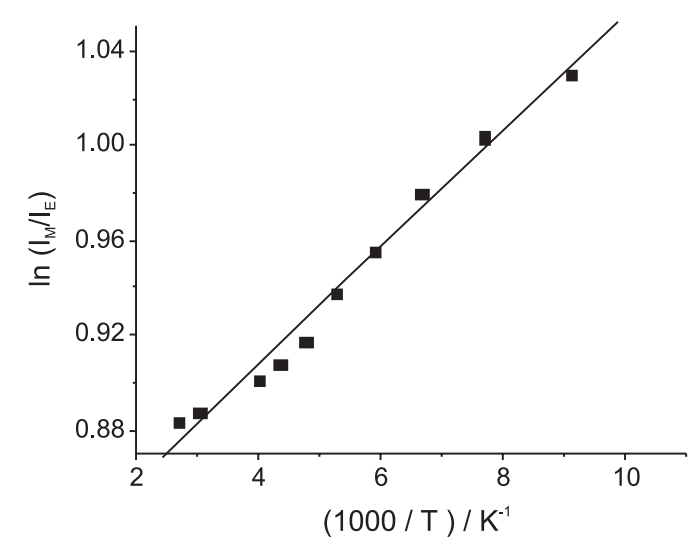

Figure 9. Arrhenius plot for PMMA-Cz fluorescence from isolated monomer $\left(\mathrm{I}_{\mathrm{M}}\right.$ at $\left.\lambda_{\mathrm{em}}=345 \mathrm{~nm}\right)$ and excimer $\left(\mathrm{I}_{\mathrm{E}}\right.$ at $\left.\lambda_{\mathrm{em}}=440 \mathrm{~nm}\right)$ (correlation factor $=0.9924)$. 


\section{PMMA-Cz relaxation processes}

The relative efficiency of each of the polymer relaxation processes depends on the temperature dependence of the rate constants for each photophysical process (in general, described by an Arrhenius function) and on the mobility of the polymer chains (which is a function of the viscoelastic properties of the medium). The fluorescence intensity, in the absence of photochemical reactions, is proportional to the ratio between the radiative efficiency and the efficiencies of the sum of the radiationless processes, and is expected to vary smoothly with temperature. ${ }^{33}$ Therefore, the abrupt changes of the rate constants at distinct temperatures indicated by the plots in Figure 8 cannot be explained unless additional extrinsic processes, such as the onsets (on heating) or cessations (on cooling) of relaxation processes of the polymer matrix in which the lumophores reside, are occurring. The link between the relaxation processes of a polymer matrix and the rate constants associated with excited state species has been attributed to electron-phonon coupling. ${ }^{23,33-37}$ In this regard, the onsets of two relaxation phenomena of PMMA are known to occur at $130-140 \mathrm{~K}$ and at $300-310 \mathrm{~K}^{35,36,42-45,50}$ The slope change at $130-140 \mathrm{~K}$ is attributed to the onset/cessation of $\gamma$-relaxations, involving rotation of short segments of the polymer chains and of $\alpha$-methyl groups bound to the main chains ${ }^{36,45,51-53}$ In addition, another relaxation process, associated with the onset/cessation of rotations of the ester groups ( $\beta$-relaxation), is also observed for PMMA around $300 \mathrm{~K}$. At still higher temperatures (370-390 K), the glass transition occurs. $35,36,42,43$

Thus, specific movements of chain-segments of PMMA are able to increase radiationless rates of isolated excited carbazolyl groups. At the same time, amplitudes of some chain motions (N.B., those from longer chain segments) may be sufficiently large to accelerate the dissociation of excimers and both ground-state and excited aggregates, resulting in a decrease of their relative emission intensity and, in some cases, an increase of the emission intensity from the isolated lumophores. Moreover, because the luminescent groups are attached to polymer chains, they will be more sensitive to motions of the polymer matrix that are in the immediate vicinity than to those that are far from it. ${ }^{34-37}$ Furthermore, the persistence of a part of the $440 \mathrm{~nm}$ emission at temperatures higher than $300 \mathrm{~K}$ suggests that some of the ground-state aggregates do not reside in places within the PMMA matrix where their association is affected by even local chain motions.

The process of the polymer matrix associated with the slope changes at $300-310 \mathrm{~K}$ in Figure 8 and attributed to the $\beta$-relaxation is also observed by the DMTA technique
(Figure 1). ${ }^{35,36,42-45,53}$ It is worth noting that this motion plays a more important role in controlling the efficiency of emission from the aggregates than from the isolated lumophores. Thus, below $300-310 \mathrm{~K}$, there is an increase of the emission intensity of the isolated lumophores and a corresponding decrease in the intensity from the aggregated groups as temperature is decreased. The relative contributions from both emissions are almost constant above $300 \mathrm{~K}$. Any motions of the polymer chains which involve a gauche $e_{+} \Leftrightarrow$ gauche_or cisoid $\Leftrightarrow$ transoid conformational change along segments where more than one carbazolyl group is directly attached must lead to either their association or dissociation. Increasing the rate of these flip-flop motions makes the dissociation of aggregates more effective because luminescence from ground state dimers and excimers requires that the molecular components of both species have very specific interlumophore distances and orientations. Finally, while the glass transition is very well defined in the DSC thermograms and by the storage modulus (E') curves of the DMTA analyses, it is practically undetected by fluorescence spectroscopy because of the overall low emission intensity.

\section{Conclusions}

We report here the photophysical characterization of a luminescent PMMA-Cz polymer synthesized by esterification of a commercially available, non-luminescent copolymer, poly(methyl methacrylate-co-methacrylic acid). The photophysical properties of the films are complex, and we could identify at least three types of emissions: fluorescence of isolated lumophores, phosphorescence of isolated lumophores (at lower temperatures), and aggregate emission from two types of dynamically formed excimers and from excitation of a ground-state dimer. The intensity of each type of emission follows a different temperature dependence, and some interconversion between aggregated species and isolated lumophores is also observed.

The temperature-dependent changes of the temporal and spectral properties of these different emissions have been used to identify the onset/cessation of two relaxation processes in PMMA-Cz films. Additionally, these relaxations could be correlated to specific motions of the polymer chains. Thus, the ability of the carbazolyl excited states to detect some relaxation processes in environments at the nanometer length scale adds important and detailed information about the specific structural changes that attend those motions and are usually described by colligative property measurements. However, one of the two detected relaxation processes, $\gamma$-relaxations at $120-130 \mathrm{~K}$ (involving rotations of short segments of the polymer chains), was 
not observed by DSC or DMTA measurements. The other process, $\beta$-relaxation at $300-310 \mathrm{~K}$, was detected by DMTA, but not by DSC. In the latter case, we concluded that the luminescence detection was successful because some of the associated carbazolyl groups dissociate at the onset of $\beta$-dissociation motions (N. B., there is a concomitant increase of emission intensity from the isolated groups and a decrease of the aggregate emission intensity). A kinetic scheme consistent with these observations has been devised.

Comparing the results obtained by DSC, DMTA and fluorescence spectroscopy, we conclude that they are complementary techniques. Whereas DSC and DMTA sense bulk properties, fluorescence reports on events involving the part of the polymer chain in the immediate neighborhood of the excited state fluorophore. This conclusion has been reached for other polymers as well; ${ }^{38-41}$ the utility of combining dynamic and static fluorescence with bulk measurements is not restricted to polyacrylate polymers.

\section{Acknowledgments}

The authors thank Professor Frank Quina from the University of São Paulo for the phosphorescence measurements. T.D.Z.A. and T.D.M. thank FAPESP, CNPq, CAPES, FAEPEX/Unicamp and MCT/PADCT/IMMP for financial support and fellowships. R.G.W. thanks the US National Science Foundation for its support of the portion of this research performed at Georgetown.

\section{Supplementary Information}

Supplementary information contains two Figures, the infrared spectrum of PMMA-Cz film (Figure S1) and the decay curves for fluorescence from a PMMA-Cz film at room temperature and at $77 \mathrm{~K}$ (Figure S2), which are available free of charge at http://jbcs.sbq.br, as a PDF file.

\section{References}

1. Wang, C. -H.; Weiss, R. G.; Macromolecules 1999, 32,7032.

2. Abdallah, D. J.; Lu, L.-D.; Weiss, R. G.; Chem. Mater. 1999, 11, 2907.

3. Keskula, H.; Polymer Modification of Rubber and Plastics, Appl. Polym. Symp.; Wiley Interscience: New York, 1968, ch. 1.

4. Vogt, O.; Pfister, M.; Marggraf, U.; Neyer, A.; Hergenroder, R.; Jacob, P.; Lab Chip. 2005, 5, 205.

5. Noh, Y. Y.; Lee, C. L.; Kim, J. J.; Yase, K.; J. Chem. Phys. 2003, $118,2853$.
6. Lee, T. W.; Park, O. O.; Kim, J.; Kim, Y. C.; Chem. Mater. 2002, $14,4281$.

7. Koulic, C.; Jerome, R.; Macromolecules 2004, 37, 888.

8. Kil, K. S.; Kim, E. S.; Kim, D. S.; Polymer (Korea) 2003, 27, 152.

9. Li, G. Z.; Peng, J. B.; Minami, N.; J. Lumin. 2001, 93, 173.

10. Ahn, T.; Song, S. Y.; Shim, H. K.; Macromolecules 2000, 33, 6764.

11. Morin, J. F.; Beaupré, S.; Leclerc, M.; Lévesque, I.; D’lorio, M.; Appl. Phys. Lett. 2002, 80, 341.

12. Miyate, S; Nalva, H. S.; Organic Electroluminescent Materials and Devices; Gordon and Breach: Tokyo, 1998.

13. Evans, N. R.; Devi, L. S.; Mak, C. S. K.; Watkins, S. E.; Pascu, S. I.; Kohler, A.; Friend, R. H.; Williams, C. K.; Holmes, A. B.; J. Am. Chem. Soc. 2006, 128, 6647.

14. Huang, C.; Zhen, C. G.; Su, S. P.; Vijila, C.; Balakrisnan, B.; Auch, M. D. J.; Loh, K. P.; Chen, Z. K.; Polymer 2006, 47,1820 .

15. Iyengar, N. A.; Harrison, B.; Duran, R. S.; Schanze, K. S.; Reynolds, J. R.; Macromolecules 2003, 36, 8978.

16. Wada, Y.; Ito S.; Yamamoto, M.; J. Phys. Chem. 1993, 97, 11164.

17. Williamson, H.; MacCallum, J. R.; Eur. Polym. J. 1993, 29, 201.

18. Yashchuk, V. M.; Bogdal, D.; Pielichowski, J.; Kononenko, Y. T.; Kushnir, K. M.; Kudrya, V. Y.; Hanusek, A.; J. Mol. Liq. 2003, 105, 185.

19. Pan, J. H.; Chiu H. L.; Wang, B. C.; J. Mol. Struct. (THEOCHEM) 2005, 725, 89.

20. Klopffer, W.; Chem. Phys. 1981, 57, 75.

21. Keyanpour, -R. M.; Ledwith, A.; Hallam, A.; North, M.; Breton, M.; Hoyle, C.; Guillet, E.; Macromolecules 1978, 1, 1114.

22. Ng, D.; Guillet, J. E.; Macromolecules 1981, 14, 405.

23. Somersall, A. C., Guillet, E. J.; Macromolecules, 1973, 6, 218.

24. Soutar, I.; Swanson, L.; Davidson, K.; Yin, J.; High Perform. Polym. 1997, 9, 353.

25. Sakai, H.; Itaya, A.; Masuhara, H.; Sasaki, K.; Kawata, S.; Chem. Phys. Lett. 1993, 208, 283.

26. Skilton, P. F.; Ghiggino, K. P.; Polym. Photochem. 1984, 5, 179.

27. Roberts, A. J.; Phillips, D.; Abdul-Rasoul, F. A. M.; Ladwith, A.; J. Chem. Soc. Faraday Trans. I 1981, 77, 2725.

28. Buchberger, E. M.; Mollay, B.; Weixelbaumer, W. D.; Kauffmann, H. F.; J. Chem. Phys. 1988, 89, 635.

29. Johnson, G. E.; J. Chem. Phys. 1975, 62, 4697.

30. Sakurovs, R.; Ghiggino, K. P.; Austr. J. Chem. 1981, 34, 1367.

31. Itaya, A.; Sakai, H.; Masuhara, H.; Chem. Phys. Lett. 1987, 138, 231.

32. Sarkar, A.; Chakravorti, S.; J. Lumin. 1998, 78, 205. 
33. Birks, B.; Photophysics of Aromatic Molecules; Wiley: New York, 1970.

34. Schurr, O.; Yamaki, S. B.; Wang, C. H.; Atvars, T. D .Z.; Weiss, R. G.; Macromolecules 2003, 36, 3485.

35. De Deus, J. F.; Souza, G. P.; Corradini, W. A.; Atvars, T. D. Z.; Akcelrud, L.; Macromolecules 2004, 37, 6938.

36. Christoff, M.; Atvars, T. D. Z.; Macromolecules 1999, 32, 6093.

37. Cossiello, R. F. C.; Kowalski, E.; Rodrigues, P. C.; Akcelrud, L.; Bloise, A. C.; DeAzevedo, E. R.; Bonagamba, T. J.; Atvars, T. D. Z.; Macromolecules 2005, 38, 925.

38. Martins, T. D.; Gulmine, J. V.; Akcelrud, L.; Weiss, R. G.; Atvars, T. D. Z.; Polymer 2006, 47, 7414.

39. Brown, G. O.; Atvars, T. D. Z.; Guardala, N. A.; Price, J. L.; Weiss, R. G.; J. Polym. Sci. Part B-Polym Phys. 2004, 42, 2957.

40. Xu, J. Q.; Luo, C. P.; Atvars, T. D. Z.; Weiss, R. G.; Res. Chem. Intermed. 2004, 30, 509.

41. Yamaki, S. B.; Atvars, T. D. Z.; Weiss, R. G.; Photochem. Photobiol. Sci. 2002, 1, 649.

42. Schmidt-Rohr, K.; Kulik, T. A. S.; Beckham, H. W.; Ohlemacher, A.; Pawelzik, U.; Boeffel, C.; Spiess, H. W.; Macromolecules 1994, 27, 4733 .
43. Hejboer, J.; Polymer 1987, 28, 509.

44. Calleja, R. D.; Riande, E. ; Roman, J. S.; J. Phys. Chem. 1992, 96,6843 .

45. Williams, J.; Eisenberg, A.; Macromolecules 1978, 11, 700.

46. Bonagamba, T. J.; Becker-Guedes, F.; Azevedo, E. R.; SchmidRohr, K.; J. Polym. Sci. Part B: Polym. Phys. 2001, 29, 2444.

47. Nayak, M. K.; Dogra, S. K.; J. Photochem. Photobiol. A: Chem. 2004, 161, 169.

48. Giro, G.; Orlandi G.; Chem. Phys. 1992, 160, 145.

49. Solaro, R.; Galli, G.; Masi, F.; Ledwith, A.; Chellini, E.; Eur. Polym. J. 1983, 19, 433.

50. Becker-Guedes, F.; deAzevedo, E. R.; Bonagamba, T. J.; Schmidt-Rohr, K.; Appl. Mag. Res. 2004, 27,383-400.

51. Tanabe, Y.; Hirose, J.; Okano, K.; Wada, Y.; Polym. J. 1970, 1, 107.

52. Baas, J. M. A.; Graaf, V. B .; Heijboer, J.; Polymer 1991, 32, 21.

53. Itagaki, H.; Obukata, N.; Okamoto, A.; Horie, K.; Mita, I.; J. Am. Chem. Soc. 1982, 104, 4469.

Received: December 3, 2007 Web Release Date: September 3, 2008

FAPESP helped in meeting the publication costs of this article. 


\section{Synthesis and Photophysical Properties of a Poly(Methyl Methacrylate)} Polymer with Carbazolyl Side Groups

Tatiana D. Martins, ${ }^{a}$ Richard G. Weiss ${ }^{*, b}$ and Teresa D. Z. Atvars ${ }^{*, a}$

${ }^{a}$ Instituto de Química, Universidade Estadual de Campinas, 13084-971 Campinas-SP, Brazil

${ }^{b}$ Department of Chemistry, Georgetown University, Washington, DC 20057-1227, USA

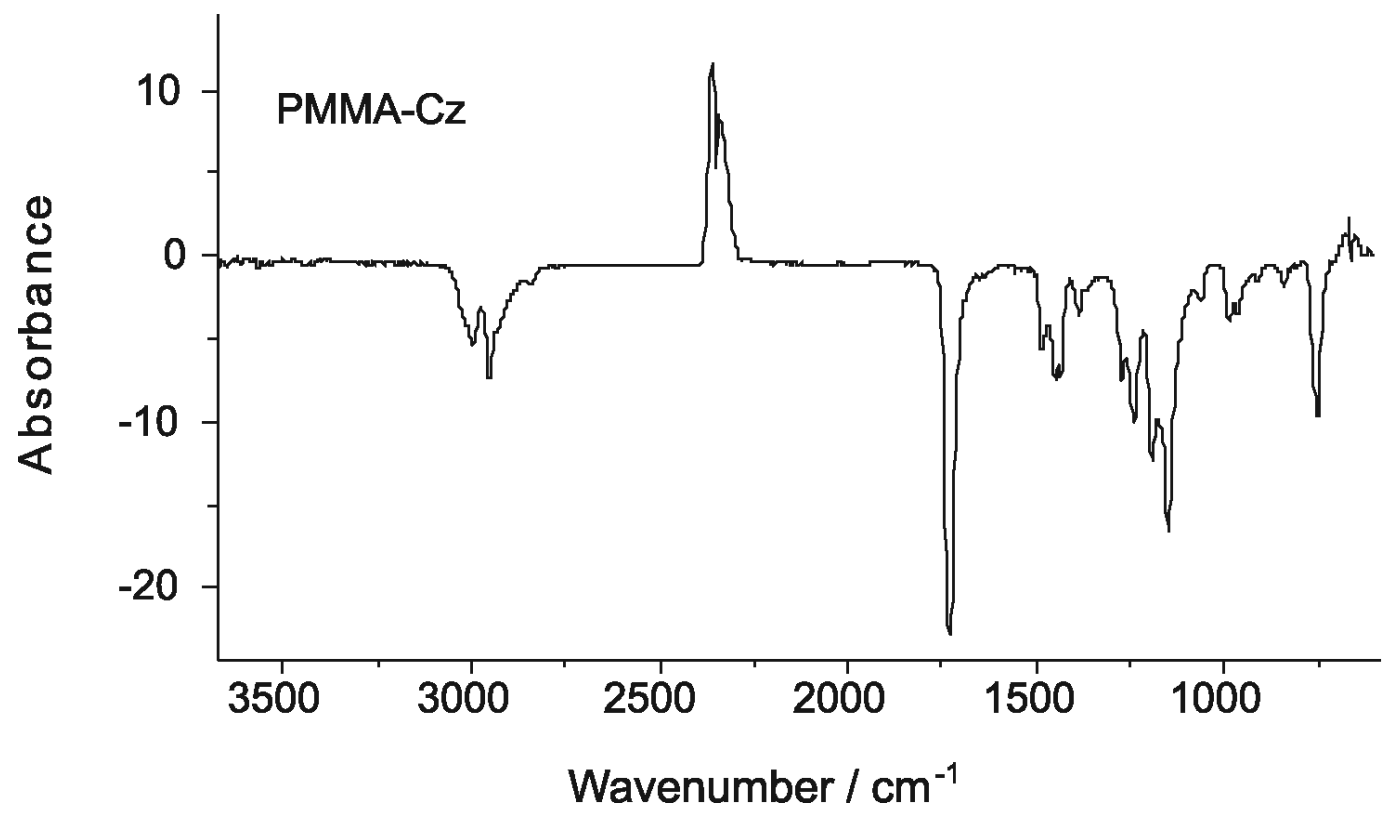

Figure S1. Infrared spectrum of PMMA-Cz film. 

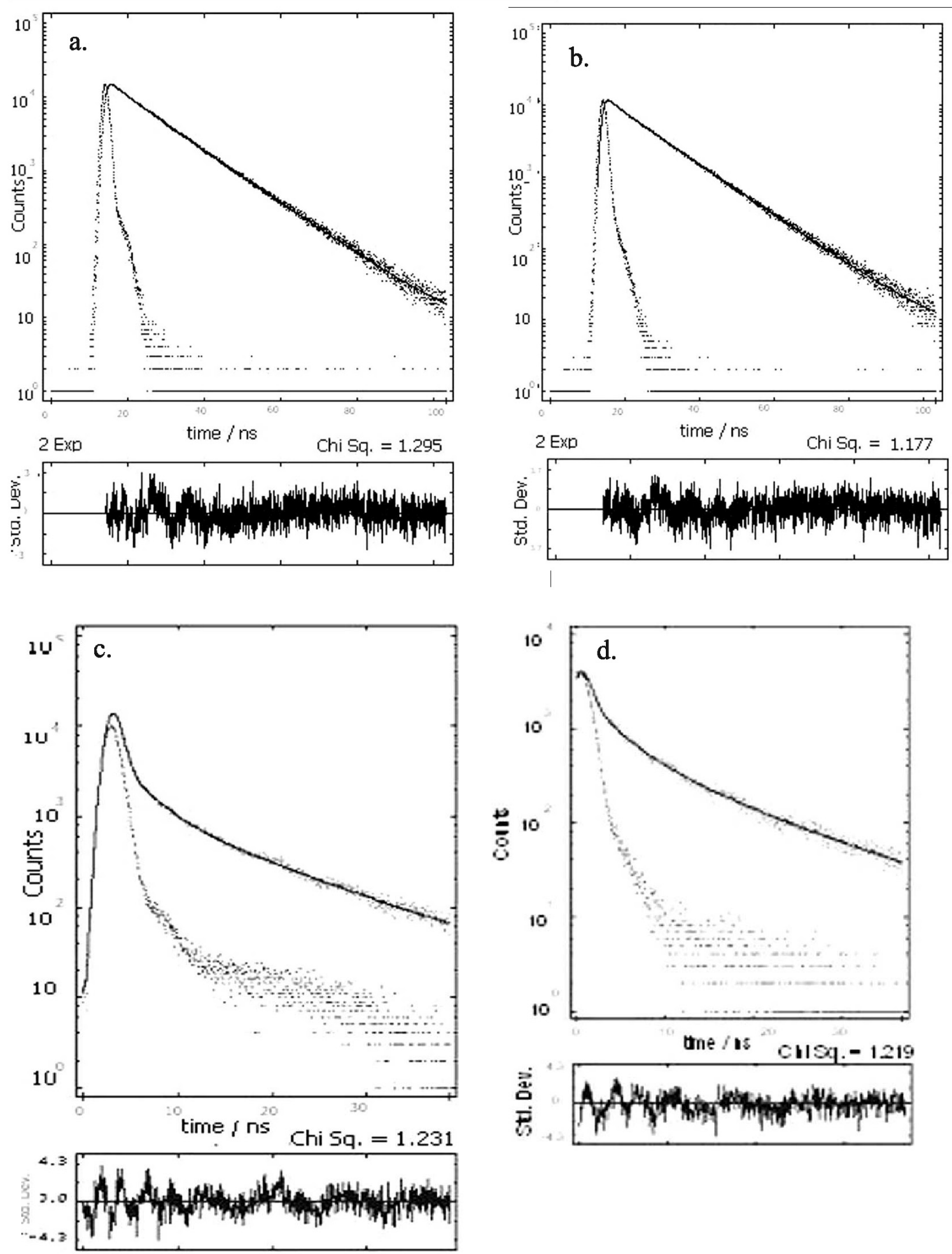

Figure S2. Decay curves for fluorescence from a PMMA-Cz film at room temperature (a,b) and $77 \mathrm{~K}(\mathrm{c}, \mathrm{d})$ and residual plots for fits to biexponential decay functions. a,b: $\lambda_{\text {exc }}=295 \mathrm{~nm}$ and $\lambda_{\mathrm{em}}=350 \mathrm{~nm} ; \mathrm{c}, \mathrm{d}: \lambda_{\mathrm{exc}}=345$ and $\lambda_{\mathrm{em}}=440 \mathrm{~nm}$. 